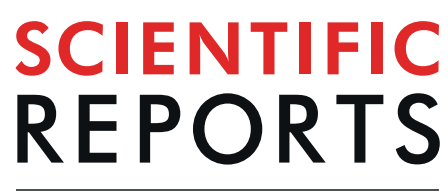

natureresearch

\title{
A highly sensitive safrole sensor based on polyvinyl acetate (PVAC) nanofiber-coated QCM
}

\author{
Kuwat Triyana ${ }^{1,2^{*}}$, Aditya Rianjanu ${ }^{1}$, Doni Bowo Nugroho ${ }^{1}$, Ahmad Hasan As'ari' ${ }^{1}$, \\ Ahmad Kusumaatmaja ${ }^{1,2}$, Roto Roto ${ }^{2,3}$, Risa Suryana ${ }^{4}$ \& Hutomo Suryo Wasisto ${ }^{5}$
}

A novel, highly sensitive and selective safrole sensor has been developed using quartz crystal microbalance (OCM) coated with polyvinyl acetate (PVAc) nanofibers. The nanofibers were collected on the QCM sensing surface using an electrospinning method with an average diameter ranging from $612 \mathrm{~nm}$ to $698 \mathrm{~nm}$ and relatively high $Q$-factors (rigid coating). Scanning electron microscopy (SEM) and atomic force microscopy (AFM) were used to analyze the PVAc nanofiber surface morphology, confirming its high surface area and roughness, which are beneficial in improving the sensor sensitivity compared to its thin-film counterpart. The as-spun PVAc nanofiber sensor could demonstrate a safrole limit of detection (LOD) of down to $0.7 \mathrm{ppm}$ with a response time of $171 \mathrm{~s}$ and a sensitivity of $1.866 \mathrm{~Hz} /$ ppm. It also showed good reproducibility, rapid response time, and excellent recovery. Moreover, crossinterference of the QCM sensor response to non-target gases was investigated, yielding very low crosssensitivity and high selectivity of the safrole sensor. Owing to its high robustness and low fabrication cost, this proposed sensing device is expected to be a promising alternative to classical instrumental analytical methods for monitoring safrole-based drug precursors.

Electrospinning is a simple and versatile technique that can create a micron-thick film containing sub-micron scale nanofibers. This technique is used to fabricate nanofibers for various applications ranging from membrane filtration to tissue engineering, and more recently, electrochemical applications ${ }^{1-6}$. The development of nanostructured materials, especially nanofiber as a sensing material, has been accelerated over the past decades ${ }^{7}$. Electrospun nanofiber film offers fibers with very small diameters and large surface areas per unit mass, which are advantageous for gas sensing ${ }^{8}$. The high specific surface area and porosity of electrospun nanofibers have sparked an increasing interest in their use as ultrasensitive gas sensors ${ }^{9-12}$. Thus, they have recently been used as active sensing layers and integrated onto various gas sensor platforms including resistive ${ }^{13}$, photoelectric ${ }^{14}$, amperometric $^{15}$, optical ${ }^{16}$, and acoustic wave $\mathrm{e}^{17,18}$. Among these devices, gravimetric sensors based on quartz crystal microbalance (QCM) have been preferred to be used for vapor detection because of their high sensitivity, fast response, inexpensive production, real-time measurement capability, and simple integration with other electronic components ${ }^{19-24}$. The QCM is basically a piezoelectric sensor platform employing acoustic-electric effects that can measure mass resolution down to the picogram level ${ }^{25}$. By modifying the QCM chip sensing area with appropriate sensing layers (e.g., polymers ${ }^{26-29}$, metal oxides ${ }^{30,31}$, and some functional materials ${ }^{32,33}$ ), specific analytes that are additionally deposited on its surface can induce a frequency shift, which can subsequently be translated into detected analyte mass according to the Sauerbrey equations ${ }^{34}$.

Safrole is a pale-yellow oil that is normally used as a precursor in the production of the amphetamine-type stimulus drug 3,4-methylenedioxyamphetamine (MDMA, "ecstasy"). Several studies have highlighted the need for the development of a better technique for the detection of drug-synthesis reactants (i.e., benzodioxol, benzyl methyl ketone (BMK), and safrole) $)^{35-38}$. Conventional analytical methods (e.g., liquid chromatography (LC), gas chromatography (GC), and gas chromatography coupled with mass spectrometry (GC-MS) ${ }^{39,40}$ ) are often

\footnotetext{
${ }^{1}$ Department of Physics, Faculty of Mathematics and Natural Sciences, Universitas Gadjah Mada, Yogyakarta, 55281, Indonesia. ${ }^{2}$ Institute of Halal Industry and System (IHIS), Universitas Gadjah Mada, Sekip Utara, Yogyakarta, 55281, Indonesia. ${ }^{3}$ Department of Chemistry, Faculty of Mathematics and Natural Sciences, Universitas Gadjah Mada, Yogyakarta, 55281, Indonesia. ${ }^{4}$ Department of Physics, Faculty of Mathematics and Natural Sciences, Sebelas Maret University, Surakarta, 57126, Indonesia. ${ }^{5}$ Institute of Semiconductor Technology (IHT) and Laboratory for Emerging Nanometrology (LENA), Technische Universität Braunschweig, Braunschweig, 38106, Germany. *email: triyana@ugm.ac.id
} 


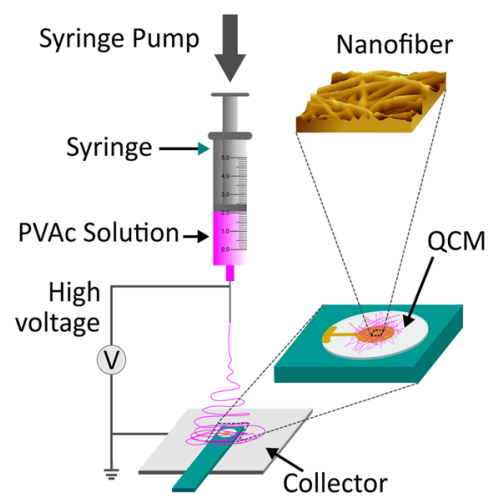

(a)

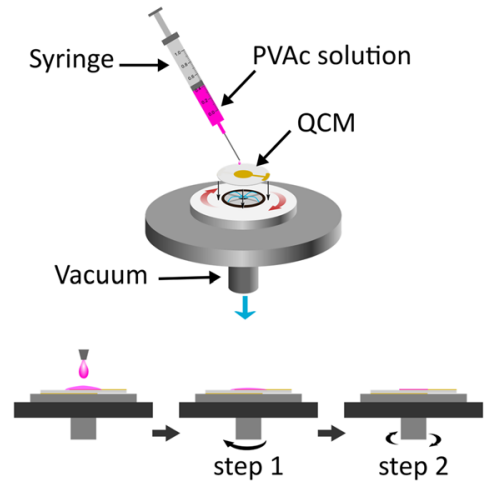

(b)<smiles>C=CCc1ccc2c(c1)OCO2</smiles><smiles>CC(=O)OC(CC(C)(C)C)C(C)(C)C</smiles>

Polyvinyl acetate

(c)

Figure 1. Schematic illustration of (a) electrospinning setup, (b) a spin-coating process, and (c) chemical structure of polyvinyl acetate (PVAc) and safrole.

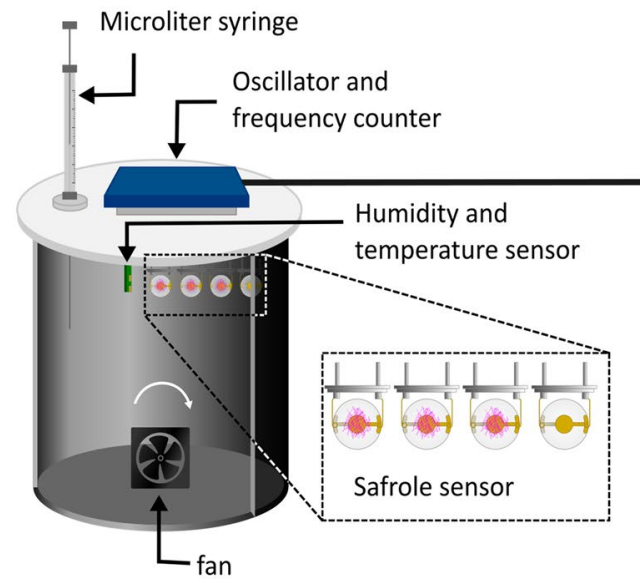

Personal Computer

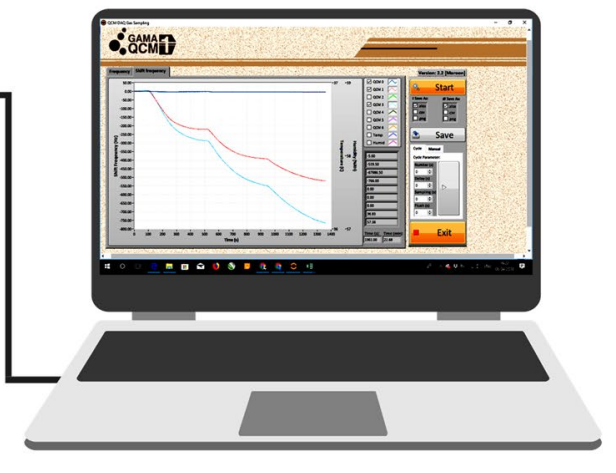

Figure 2. Measurement setup of the quartz crystal microbalance system for gas or vapor sensing.

employed for forensic safrole testing. However, these techniques are costly, not portable, and challenging to be operated in real-time. Therefore, the development of a rapid, reliable, low-cost, and real-time safrole sensor is needed. In our previously reported studies ${ }^{37,38}$, although nanofiber-based QCM safrole sensors had been developed and tested, their performance was still unsatisfactory in terms of sensitivity and selectivity, due to poor intermolecular interaction between safrole molecules and sensing layers (i.e., polyacrylonitrile (PAN) nanofiber). Therefore, polyvinyl acetate (PVAc)-based nanofiber membrane was developed and employed in this work to overcome this issue. This hydrophobic polymer could be easily electrospun on the active layer of QCM. The hydrophobicity of PVAc is essential since the response of the QCM vapor sensor is heavily interfered by water vapor. For the sensing mechanism, the oxygen molecules in PVAc structure will act as a Lewis base that can interact with safrole (Lewis acid). A Lewis base is an electron pair donor, while a Lewis acid is an electron pair acceptor $^{41}$. They can react with each other forming a covalent bond, where both electrons are provided by the Lewis base. In case of their molecular orbitals, Lewis acids and bases have an unoccupied low-energy atomic states and occupied relatively high energy atomic states, respectively. A lone electron pair (i.e., a pair of valence electrons that are not shared with another atom in a covalent bond) in oxygen sites from each PVAc unit may interact strongly with two protons located between two oxygen atoms of safrole. Furthermore, to demonstrate its feasibility as a practical sensor in a real field, cross-sensitivity measurements toward other non-target gases were also conducted and evaluated.

\section{Results and Discussion}

PVAc membrane analysis. Figure 3 displays the SEM images of both PVAc thin-film (NF 0) and PVAc nanofibers (NF 1, NF 2, and NF 3). Continuous nanofiber structures with a smooth surface are clearly seen from the inset images of Fig. 3(b-d). The mean diameters of the nanofiber samples are listed in Table 1, revealing similar average diameters ranging from $612 \mathrm{~nm}$ to $698 \mathrm{~nm}$. Meanwhile, the morphology of PVAc thin-film produced by a spin coating process revealed a smooth surface with several pores (see Fig. 3(a)). Both types of structures presented relatively homogenous features in their physical morphology. Furthermore, they also possessed 3D pore architectures that led to easy accessibility and fast exposure to the gases, rendering the PVAc nanostructured 


\begin{tabular}{|l|l|l|l|l|}
\hline Sample & NF 0 & NF 1 & NF 2 & NF 3 \\
\hline Membrane form & Thin-film & Nanofiber & Nanofiber & Nanofiber \\
\hline Deposition time $(\mathrm{s})$ & 30 & 5 & 15 & 25 \\
\hline Diameter $(\mathrm{nm})$ & - & $631 \pm 85$ & $612 \pm 98$ & $698 \pm 70$ \\
\hline Frequency shift $(\mathrm{kHz})$ & 16.3 & 2.0 & 16.2 & 21.0 \\
\hline Deposited mass $(\mu \mathrm{g})$ & 20.4 & 2.5 & 20.2 & 26.2 \\
\hline Calculated thickness $(\mathrm{nm})$ & 606 & 74 & 599 & 778 \\
\hline
\end{tabular}

Table 1. Parameters of developed PVAc sensors (i.e., NF 0, NF 1, NF 2, and NF 3) based on different membrane structures (i.e., thin-film and nanofibers). The density of PVAc and the surface area of QCM electrode are $1.19 \mathrm{~g} / \mathrm{cm}^{3}$ and $0.283 \mathrm{~cm}^{2}$, respectively.
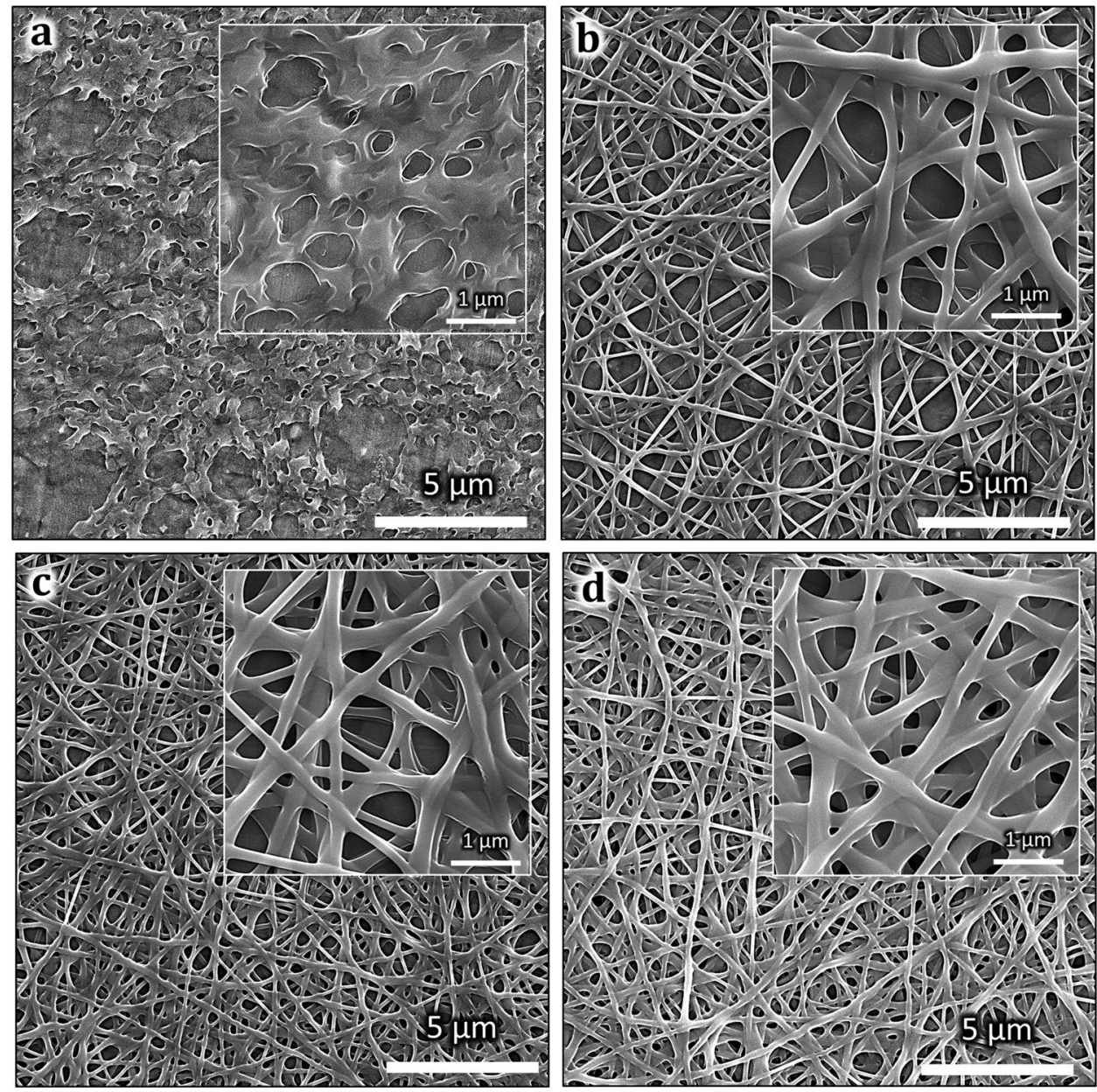

Figure 3. SEM images of (a) PVAc thin-film (NF 0), (b) PVAc nanofiber (NF 1), (c) NF 2, (d) NF 3 (inset figure is the magnified view of the structures).

membrane a potential candidate for application in routine vapor detection. The 3D porous structure increased the sensor surface area and enhanced the contact area between safrole molecules and sensing sites. Thus, it could improve the sensing performances. Table 1 also shows the sensing layer thickness $h_{\text {sensor }}$, which is calculated using Eq. (1)

$$
h_{\text {sensor }}=\frac{m_{\text {sensor }}}{\rho_{\text {sensor }} \times A_{Q C M}}
$$

where $m_{\text {sensor }}, \rho_{\text {sensor }}$, and $A_{Q C M}$ are the deposited sensor mass (see Table 1$)$, the density of PVAc $\left(1.19 \mathrm{~g} / \mathrm{cm}^{3}\right)$, and the surface area of QCM electrodes $\left(0.283 \mathrm{~cm}^{2}\right)$, respectively.

Figure 4(a,b) show the AFM analyses of deposited PVAc thin film and nanofibers. In the case of the PVAc thin-film (NF 0), a relatively homogeneous surface with several porous structures was obtained. The root mean square roughness $\left(R_{R M S}\right)$ of the PVAc thin-film sample was found at about $140 \mathrm{~nm}$, with a $415 \mathrm{~nm}^{2}$ surface area 

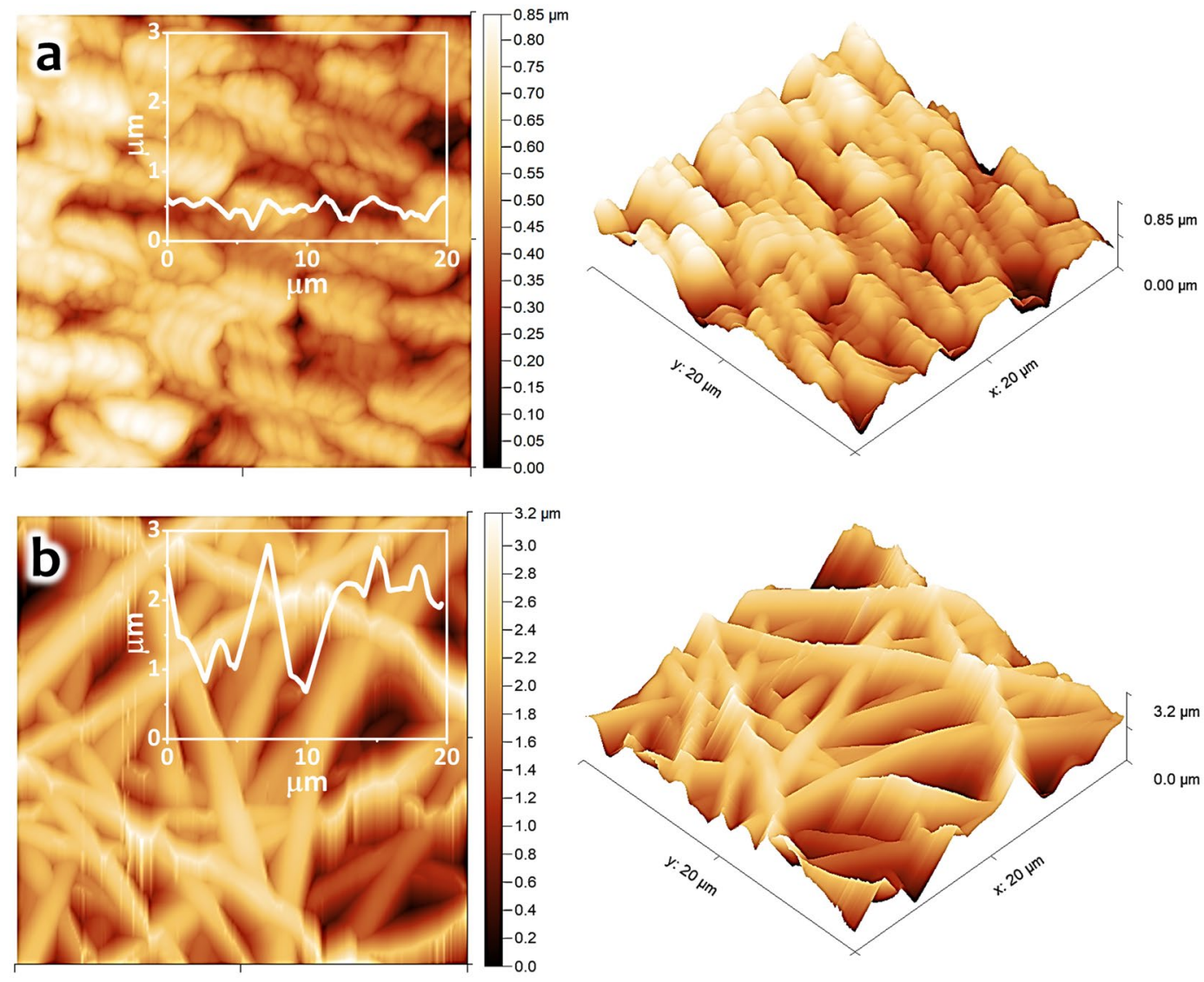

Figure 4. Top-view and cross-sectional AFM images of the PVAc nanostructures: (a) NF 0 and (b) NF 2.

(Fig. 4(a)). To the contrary, the PVAc nanofiber sample (NF 2) was clearly found to be rougher than its thin-film surface, which was confirmed by its $\mathrm{R}_{\mathrm{RMS}}$ of about $520 \mathrm{~nm}$, with a $572 \mathrm{~nm}^{2}$ surface area (Fig. 4(b)). It should be mentioned that both $R_{R M S}$ values obtained for thin-film and nanofiber samples were determined on the basis of the $20 \times 20 \mu \mathrm{m}^{2}$ of the AFM images. Besides, because of their similar morphologies shown in Fig. 3(b-d), other two nanofiber samples (NF 1 and NF 3 ) are expected to have similar roughness and porosity characteristics to sample NF 2 .

The conductance and susceptance spectra were measured to analyze the resonant characteristics of the QCM-based PVAc sensor prior to safrole exposure as shown in Fig. 5(a,b). Accordingly, quality factor (Q-factor) of the resonator could be extracted as the ratio of the peak frequency to the half bandwidth in the conductance spectrum. It is well-known from micro-/nanoelectromechanical systems (MEMS/NEMS), that higher Q-factor is preferable for sensors to have better stability, smaller frequency noise, and less energy loss ${ }^{31,42}$. The measured Q-factors of the QCM-based PVAc sensors in normal ambient air were 47818, 32951, 48059, and 33093 for NF 0 , NF 1, NF 2, and NF 3, respectively. In comparison with other typical MEMS/NEMS-based resonators made of piezoresistive silicon cantilevers ${ }^{43-45}$, electrothermal silicon cantilevers ${ }^{46-48}$, and vertical silicon nanowires ${ }^{49-51}$, the piezoelectricity QCM sensors (quartz) exhibited superiority in terms of Q-factor, even after being functionalized with PVAc thin-films or nanofibers. This demonstrated that both polymer deposition techniques used in this work (i.e., spin coating and electrospinning) could offer a solution for creating stable hybrid polymer/semiconductor MEMS-based devices with low-frequency noise. It should be noted that for such silicon microcantilever structures coated with photoresist in a drop-casting method, their Q-factors may deteriorate by one order of magnitude ${ }^{52}$.

Safrole exposure assessment. Figure 6(a) shows the measured dynamic responses of QCM sensors coated with PVAc thin-film (NF 0) and PVAc nanofiber (NF 2) under exposure to safrole vapors. To directly investigate the influence of surface-to-volume enhancement of the nanofibers, both samples were previously treated with similar loading depositions (i.e., $\sim 16 \mathrm{kHz}$ ). During the gas sensing test, the safrole concentration was initially set at $10 \mathrm{ppm}$ and subsequently increased to $50 \mathrm{ppm}$. As expected, both sensors (NF 0 and NF 2) experienced frequency shifts toward lower values. However, from the sensor responses, it was clearly shown that the nanofiber structure (NF 2) exhibits larger frequency shifts (i.e., around 1.5 times) compared to its thin-film counterpart (NF 0), even though PVAc deposition masses for both devices were kept at a similar level. At 50 ppm safrole concentration, the frequencies of NF 0 and NF 2 samples dropped by $42 \mathrm{~Hz}$ and $65 \mathrm{~Hz}$, respectively, from their initial value, where the gas had not been injected into the sealed chamber. This result has confirmed the importance of having larger surface area and porous surface structures made as nanofibers compared with 

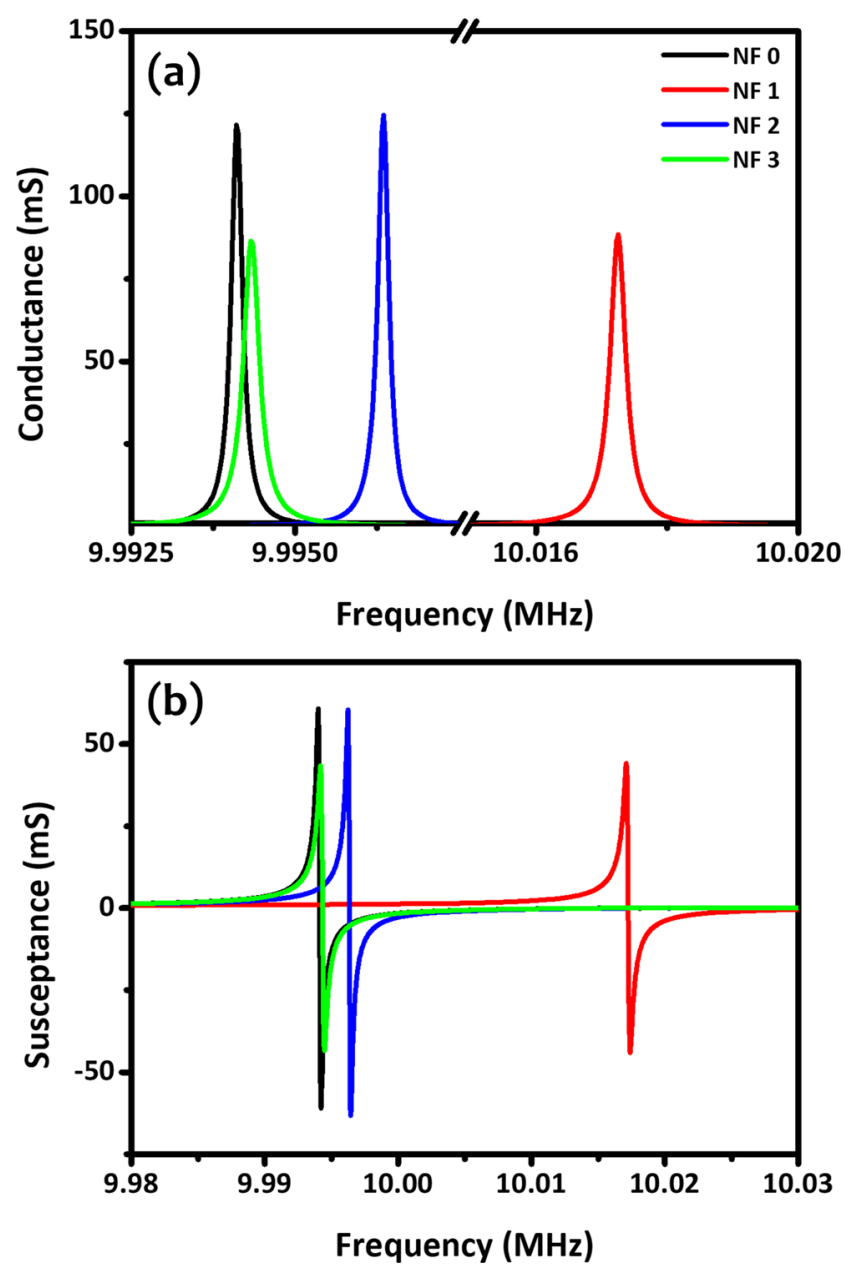

Figure 5. Frequency characteristics of all sensors (NF 0-NF 3) measured in (a) conductance and (b) susceptance modes.

ordinary thin film ${ }^{53}$. This argument for the response difference between these two sensors has been supported by the SEM (Fig. 3(a,c)) and AFM images (Fig. 4(a,b)). The SEM images indicate that the thin-film sample had a relatively smooth surface with a few pores, while the nanofiber sample possessed more membrane pores (space between the nanofibers). Moreover, the AFM images show that the nanofiber structure had a rougher surface and higher surface area compared to the thin film.

To investigate the influence of loading deposition on QCM-based PVAc nanofiber sensor performance, the electrospinning parameters were varied as listed in Table 1 . The loading deposition was increased from NF 1 to NF 3. Figure 6(b) depicts the dynamic responses of three sensors with different nanofiber structures under exposure to increasing safrole concentrations from 10 to $1000 \mathrm{ppm}$. It shows that the response of the PVAc nanofiber sensors could be enhanced by increasing the loading depositions. For instance, at $50 \mathrm{ppm}$ safrole concentration, the responses (changes of resonance frequency) of the sensors were measured to be $18 \mathrm{~Hz}, 71 \mathrm{~Hz}$, and $85 \mathrm{~Hz}$ for NF 1, NF 2, and NF 3 sensors, respectively. Moreover, by increasing the safrole concentration up to $1000 \mathrm{ppm}$, a larger frequency change in the QCM sensors was obtained, reaching up to almost $2 \mathrm{kHz}$ (Fig. 6(c)). The sensitivity, which is defined as the slope of the linear correlation between the safrole concentration and its frequency change, also increased from NF 1 to NF 3 (i.e., $S_{\mathrm{NF} 1}=0.37 \mathrm{~Hz} / \mathrm{ppm}, S_{\mathrm{NF} 2}=1.44 \mathrm{~Hz} / \mathrm{ppm}$, and $S_{\mathrm{NF} 3}=1.86 \mathrm{~Hz} / \mathrm{ppm}$ ). A good linear correlation between loading deposition (frequency shift after coating) and sensor sensitivity is shown in Fig. 6(d) with a correlation coefficient $\left(R^{2}\right)$ of 0.997 . The increase in loading depositions indicates that more PVAc molecules were successfully deposited on the QCM chips. The feasibility of intermolecular interaction between the active layer and the analyte was therefore enhanced, resulting in higher frequency shifts.

Proposed sensing mechanism. Physisorption or physical adsorption between safrole gas and PVAc can be an important adsorption mechanism toward an understanding of the sensing behavior of this developed hybrid PVAc/QCM device. From FTIR characterization, we could confirm that there was no chemical interaction between PVAc nanofiber and safrole molecules. Figure $7(\mathrm{a}-\mathrm{c})$ show the IR spectra of PVAc, safrole, and PVAc exposed to safrole, respectively. PVAc nanofiber (Fig. 7(a)) had an absorbance at the peak of 1731-1733 $\mathrm{cm}^{-1}$, which was attributed to an acetate ester carbonyl group $(\mathrm{C}=\mathrm{O} ; \mathrm{C}-\mathrm{O})$. The other peaks could be found 

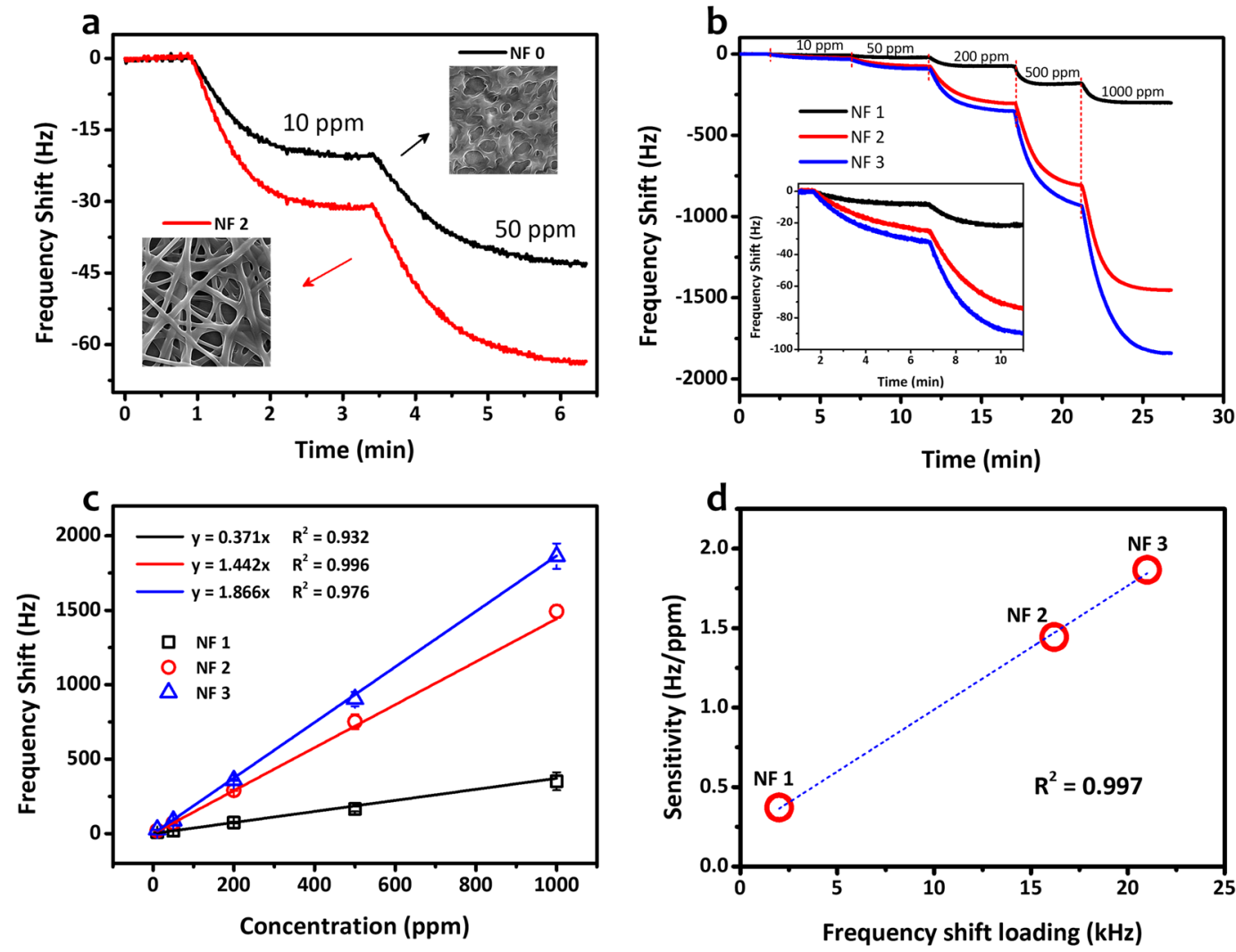

Figure 6. QCM-based PVAc safrole sensor characteristics. (a) Frequency responses of PVAc thin-film (NF 0) and PVAc nanofiber (NF 2). (b) Dynamic responses of PVAc nanofiber sensor for increasing safrole concentration (inset: zoom at low concentration). (c) Frequency shift of QCM PVAc safrole sensor in different safrole concentrations. (d) Sensitivity of QCM PVAc nanofiber sensor for increasing loading depositions.

at $1433-1435 \mathrm{~cm}^{-1}(\mathrm{C}-\mathrm{H}), 1371-1372 \mathrm{~cm}^{-1}(\mathrm{C}-\mathrm{H}), 1227-1235 \mathrm{~cm}^{-1}(\mathrm{C}-\mathrm{O})$, and $1019-1021 \mathrm{~cm}^{-1}(\mathrm{C}-\mathrm{O})^{54}$. IR spectrum of safrole is shown in Fig. 7(b), with peaks at $1501 \mathrm{~cm}^{-1}, 1490 \mathrm{~cm}^{-1}$, and $1441 \mathrm{~cm}^{-1}$, that are related to stretching of the carbon double bond $(\mathrm{C}=\mathrm{C})$, while an additional peak at $3077 \mathrm{~cm}^{-1}$ can be attributed to stretching of the hydrocarbon $(\mathrm{C}-\mathrm{H})$, which is an aromatic group. Furthermore, safrole has an aldehyde group that is depicted by peaks at $2775 \mathrm{~cm}^{-1}, 2838 \mathrm{~cm}^{-1}, 2895 \mathrm{~cm}^{-1}$, and $2978 \mathrm{~cm}^{-1}$. Figure 7 (c) shows the peak characteristics of both PVAc nanofiber and safrole. The peaks observed in the PVAc nanofiber exposed to safrole FTIR spectra were close to those in the spectrum of PVAc. The peaks detected at $1504 \mathrm{~cm}^{-1}$ dan $1490 \mathrm{~cm}^{-1}(\mathrm{C}=\mathrm{C})$ were attributed to the aromatic ring, whereas peaks at $2955 \mathrm{~cm}^{-1}$ and $2854 \mathrm{~cm}^{-1}(\mathrm{C}-\mathrm{H})$ corresponded to the aldehyde group of the safrole. These results confirmed that no chemical reaction occurred when PVAc nanofiber was exposed to safrole. The only possible interaction was intermolecular interaction, which cannot be detected using the FTIR method.

There may be two scenarios by which safrole is received by the sensor as illustrated in Fig. 8. First, the carbonyl group, an ester of PVAc, has an $\mathrm{O}$ atom with a higher electronegativity than the $\mathrm{C}$ atom of safrole. In this situation, the $\mathrm{O}$ atom has a partial negative charge $\left(\delta^{-}\right)$and the $\mathrm{C}$ atom has a partial positive charge $\left(\delta^{+}\right)$. Consequently, dipole-dipole interactions can occur. Furthermore, one $\mathrm{O}$ atom of PVAc monomer can interact with the carbon atoms of two safrole molecules, so that one monomer of PVAc can interact with four safrole molecules. Because of these phenomena, PVAc can interact more readily than PAN, used in former works ${ }^{37}$. Secondly, the molecular structure may influence the interaction and cause different sensor sensitivities to the analyte. PVAc is a polymer that has a polar structure, so that interactions will be stronger with analyte molecules that also have a polar structure $^{55}$. Each analyte has a unique molecular structure affecting its polarity.

Other sensor characteristics. The LOD and the limit of quantification (LOQ) are determined based on the standard deviation and the slope of the plot in Fig. 6(c) ${ }^{56}$. The LOD and LOQ are expressed as $3.3 \sigma / S$ and $10 \sigma / S$, respectively, where $\sigma$ is the standard deviation of the blank air measurement (i.e., $0.37 \mathrm{~Hz}$ for NF 3 ) and $S$ is the sensor sensitivity (i.e., $1.866 \mathrm{~Hz} / \mathrm{ppm}$ for NF 3). Thus, the LOD and LOQ of QCM modified with PVAc nanofiber (NF 3 ) could be calculated to be $0.7 \mathrm{ppm}$ and $2 \mathrm{ppm}$, respectively.

Compared to other materials, the PVAc nanofiber sensors produced by electrospinning exhibited the highest sensitivity. While integrating PAN nanofiber on QCM devices only resulted in sensor sensitivities of $0.035 \mathrm{~Hz} /$ $\mathrm{ppm}^{37}$, using PVAc nanofiber (NF 3) could deliver a sensitivity of up to $1.86 \mathrm{~Hz} / \mathrm{ppm}$, which demonstrated a remarkable increase of $\sim 53$ times. The explanation of this phenomenon has been discussed previously in the proposed sensing mechanism section. 

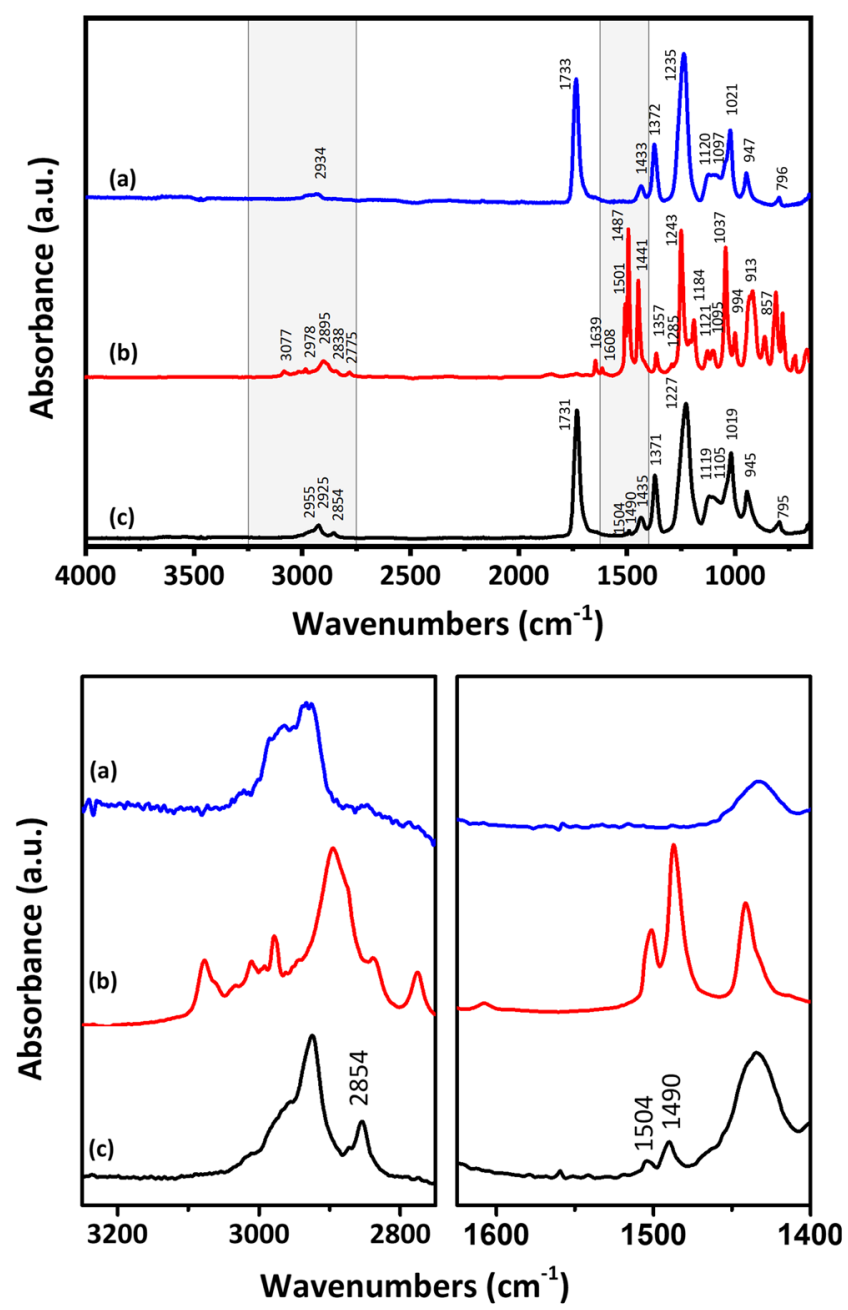

Figure 7. FTIR spectra of (a) PVAc nanofiber, (b) safrole, and (c) PVAc exposed to safrole vapor.

To investigate their sensing reproducibility, the PVAc nanofiber sensors were exposed to safrole vapors at a fixed concentration of $50 \mathrm{ppm}$ and multiple gas injections (up to 20 times). Figure 9(a) shows the measured signals of three different QCM-based PVAc sensors during the reproducibility test. The standard deviations were found to be 11,6 , and $5 \%$ for the response values of NF 1, NF 2, and NF 3, respectively. The slight fluctuation in frequency shift suggests that all QCM chips exhibited high sensing reproducibility.

The full sensor response and recovery characteristics are important parameters in the performance of gas sensors. Thus, to investigate them in the PVAc sensors, we modified the gas sensing configuration. The response-recovery investigation was performed by modifying the sensor chamber in accordance with previously reported setup ${ }^{9,24}$. The safrole concentration was predetermined at $50 \mathrm{ppm}$. The response and recovery behaviors of the NF 2 sensor are depicted in Fig. 9(b), where full recovery could be obtained by the sensor after being exposed to safrole. Moreover, the response and recovery times for the NF 2 sensor were measured to be 171 and $475 \mathrm{~s}$, respectively. It should be noted that the sensor response or recovery time is defined as the time required for the sensor to reach $90 \%$ of its maximum value $\left(t_{90}\right)$ during response or recovery activity. In comparison to typical conductometric metal oxide gas sensors ${ }^{57,58}$, which need longer response/recovery times (10-120 min), our PVAc-coated QCM sensors could, apparently, react faster to exposing gas.

Figure 9(c) shows the response of the NF 3 sensor to safrole vapor at $50 \mathrm{ppm}$, which fits the first-order instrument response. The time constant $(\tau)$ was found to be $78 \mathrm{~s}$ for this device toward safrole. For other analytes, the sensor time constant also differed, depending on the interaction between sensor and measured gas molecules. Regarding sensing, we believe that the properties of the analyte (i.e., boiling points) influenced the response times of the sensor. Figure 9(d) shows the correlation graph between the analyte boiling points and the relaxation time of the QCM-based PVAc sensor. The results indicate that the relaxation time increases linearly with the rise of the analyte boiling point for most of the analytes. The anomaly appears for the methanol analyte, for which factors other than analyte boiling point may have influenced the relaxation time. Thus, in-depth investigation into this matter will be necessary for our next study. Moreover, the results presented here only apply when the sensor responses were measured using static batch method. 


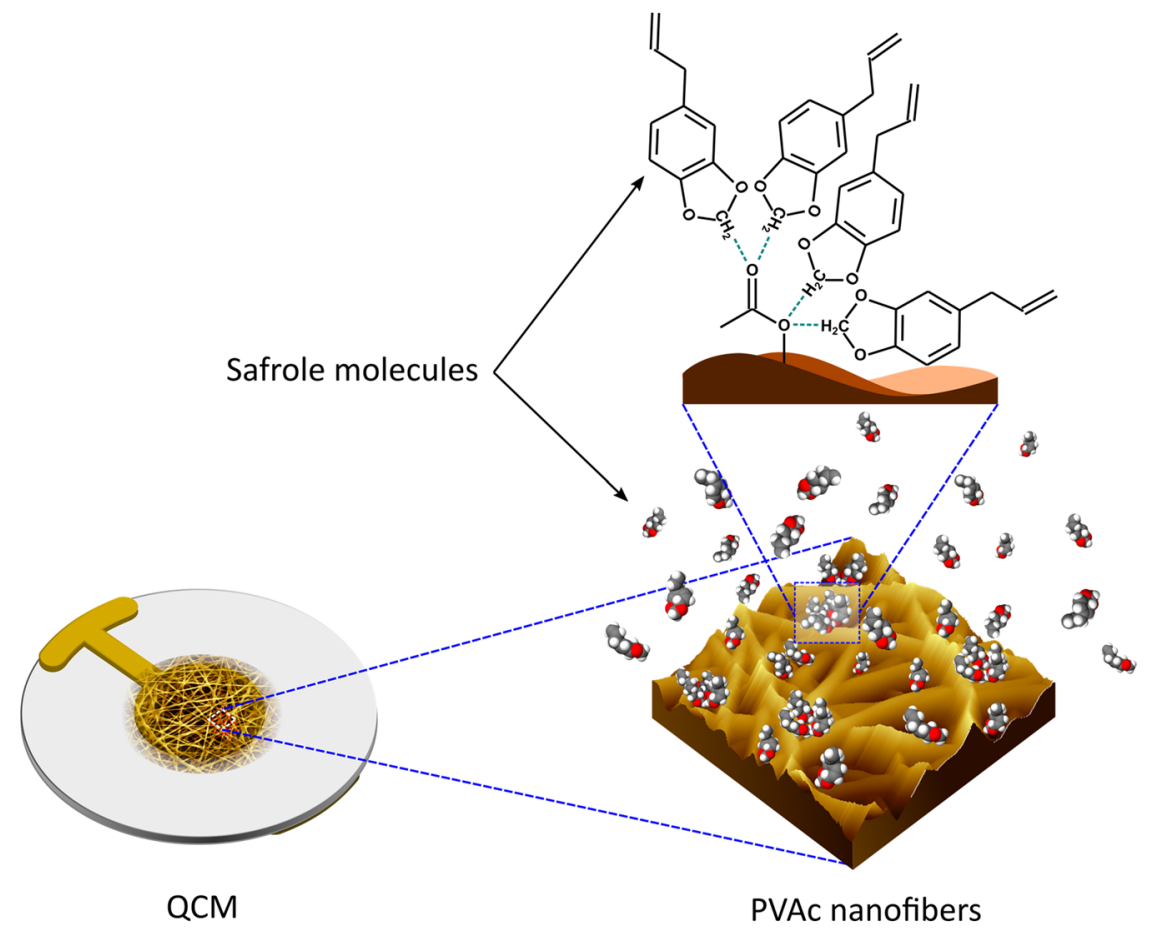

Figure 8. Schematic representation of the proposed interaction mechanism between the PVAc nanofiber and safrole molecules.

Apart from sensitivity and response/recovery time, reaction selectivity of the sensors plays an important role to examine the device practicability in the field. Therefore, cross-sensitivity experiments were conducted with various volatile organic compound (VOC) gases at $50 \mathrm{ppm}$ concentration, which are usually present in ambient air (US EPA). As the sensor under test, we used the NF 2 sensor, whose results are shown in Fig. 10(a). Extremely high selectivity was observed for safrole gas, whose measured sensitivity is $1.44 \mathrm{~Hz} / \mathrm{ppm}$. Meanwhile, the PVAc nanofiber sensor showed a very low response toward other gases (e.g., xylene, formaldehyde, toluene, benzene, ethanol, acetone, methanol, and water), for which a sensitivity of below $0.065 \mathrm{~Hz} / \mathrm{ppm}$ was normally obtained. Thus, it can be concluded that the PVAc nanofiber sensor (NF 2) showed an excellent selectivity to safrole vapor.

As sensor robustness is very important for real device applications, the PVAc safrole sensors were regularly tested with $50 \mathrm{ppm}$ safrole vapor every 5 days over a 30 day period to evaluate their long-term stability. Figure 10(b) displays the responses (frequency shifts) as a function of time over 30 days. The average responses of the PVAc sensors (NF 1, NF 2, and NF 3) were measured to be 19, 72, and $86 \mathrm{~Hz}$, with relative errors of 9, 4, and $5 \%$, respectively. The sensor still displayed a good response with an almost constant value of resonance frequency after 30 days of gas sensing measurement, indicating that the employed QCM system is highly stable for long-term use.

\section{Conclusions}

PVAc nanofibers have been successfully fabricated through a simple and facile electrospinning technique, in which their sensing characteristics toward safrole vapor have been investigated. The high surface area and porous structure of the nanofibers clearly influence the safrole sensor performance. Compared to the device coated with PVAc thin-film, the sensors functionalized with PVAc nanofibers exhibited an excellent enhancement of safrole detection. The response sensitivity of the PVAc nanofiber sensor is 1.5 times higher than that of PVAc thin-film sensor. The detection limit of the sensor could reach as low as $0.7 \mathrm{ppm}$, with up to $1.866 \mathrm{~Hz} / \mathrm{ppm}$ sensitivity toward safrole. As-prepared sensors have shown good reproducibility, long-term stability, and high selectivity toward others analytes. All in all, the QCM sensing chip modified with electrospun polymers may offer a new strategy in real-time sensing of drug precursors.

\section{Materials and Method}

Materials. Polyvinyl acetate (PVAc) with a molecular weight of 500,000 g/mol was supplied by SigmaAldrich. N,N-dimethylformamide (DMF) for dissolving PVAc was purchased from Merck (Germany). Safrole analyte with $96 \%$ purity, was supplied by the Indonesian National Police, Jakarta, Indonesia. All chemicals were used as received without further purification. The AT-Cut QCM sensors with gold electrodes and $10 \mathrm{MHz}$ base resonant frequency were purchased from OpenQCM, Novaetech. R\&D, Napoli, Italy.

Preparations of QCM PVAc nanofiber and thin-film. The PVAc solution was prepared using dimethylformamide (DMF) at a concentration of $15 \%(\mathrm{w} / \mathrm{w})$ and subsequently electrospun on a QCM substrate at an applied voltage of $15 \mathrm{kV}$ and a needle-to-collector distance of $15 \mathrm{~cm}$. The electrospinning process (Fig. 1(a)) was 
a
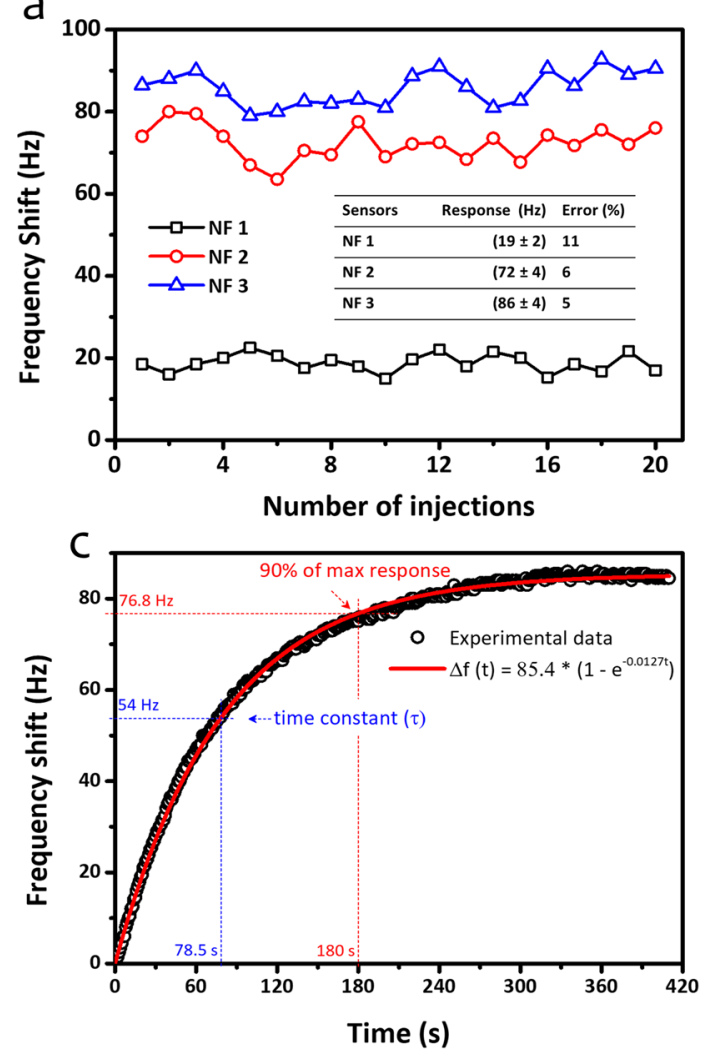
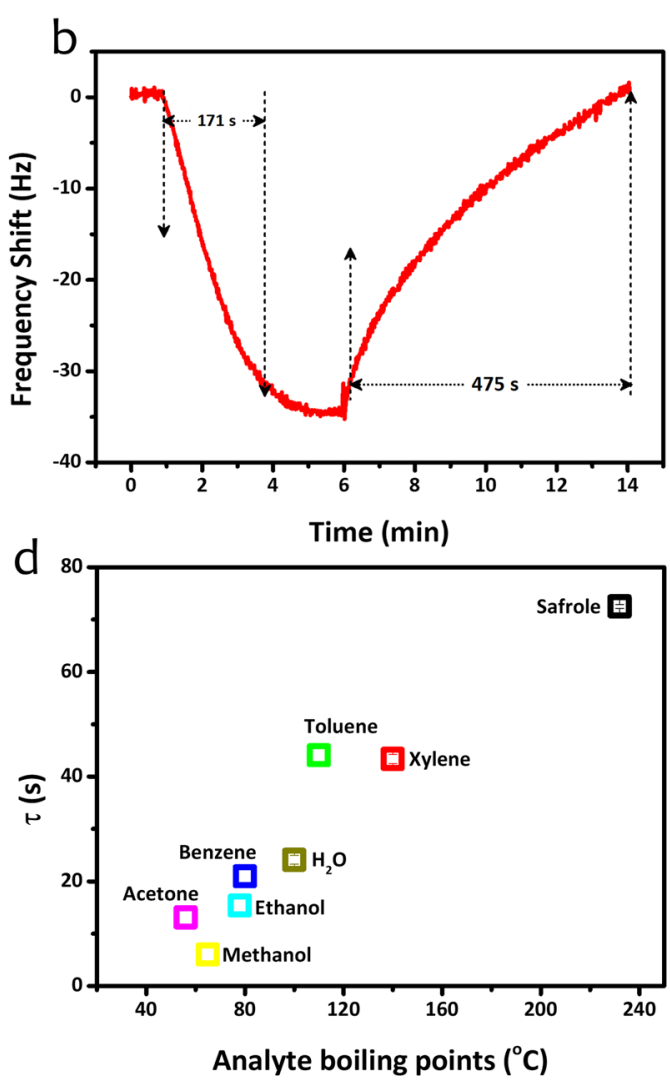

Figure 9. (a) Reproducibility, (b) response-recovery, (c) response time of NF 2 samples exposed to $50 \mathrm{ppm}$ of safrole, and (d) time constant of the NF 2 sensor exposed to various analytes corresponding to its boiling points.

carried out for 5, 15, and 25 seconds and denoted as NF 1, NF 2, and NF 3, respectively. After being collected on the chip, the as-spun nanofibers were then dried overnight prior to their use in sensor assessments.

To investigate the effect of enhanced surface area by nanofibers on QCM sensor performance, besides the electrospinning technique, a spin coating method was also utilized for producing a PVAc membrane with a different structure (i.e., thin-film) using Compact Spin Coater VTC-100 (see Fig. 1(b)). The PVAc thin-film sensor was fabricated using the same parameters as previously reported ${ }^{24}$. The two-step spin coating process was employed during the thin-film membrane fabrication to obtain a deposited film mass similar to that of the PVAc nanofiber sample created by electrospinning. Spinning speeds of $500 \mathrm{rpm}$ and $5000 \mathrm{rpm}$ were set during the first and second spin processes for $5 \mathrm{~s}$ and $30 \mathrm{~s}$, respectively. The resulting PVAc thin-film membrane was then denoted as NF 0. The chemical structures of polyvinyl acetate (PVAc) and safrole are shown in Fig. 1(c).

Sensor apparatus for safrole detection. A schematic diagram of the PVAc QCM testing system is shown in Fig. 2. The PVAc QCM sensor was installed inside a testing chamber (2 L) using similar environmental conditions as described in literature ${ }^{24,28}$. A ten microliter Hamilton syringe (Model 701 RN SYR) was used for analyte injection. The concentration of an injected analyte in the testing chamber was calculated according to Eq. $(2)^{53,59}$ :

$$
C=\left(\frac{22.4 \rho V_{s} T}{273 M V}\right) \times 10^{3}
$$

where $C$ is the analyte concentration in ppm, $\rho$ is the density of liquid analyte in $\mathrm{g} / \mathrm{mL}, V_{s}$ is the volume of the analyte in $\mu \mathrm{L}, T$ is the Kelvin temperature in the testing chamber, $M$ is the molecular weight of analyte in $\mathrm{g} / \mathrm{mol}$, and $V$ is the chamber volume in L. This equation assumes that the safrole is fully evaporated in the chamber after injection. The responses of the QCM sensors were tested by monitoring the change in the resonance frequency, as measured by a frequency counter. The change in the resonant frequency of the QCM sensor is related to the change in mass loading on the QCM sensor chip. The frequency change data were recorded with a PC equipped with the LabVIEW graphical programing language. To desorb the analyte vapor from the QCM sensing chips, dry ambient air was used during purging.

Sample characterization. The nanofiber morphology of the samples was analyzed using scanning electron microscopy (SEM, JEOL JSM-6510). Their roughness was characterized using atomic force microscopy (AFM, XE-70, Park System Corp., South Korea). The conductance and susceptance of the QCM were measured using a vector network analyzer (Omicron-Lab Bode 100), while Fourier-transform infrared spectroscopy 

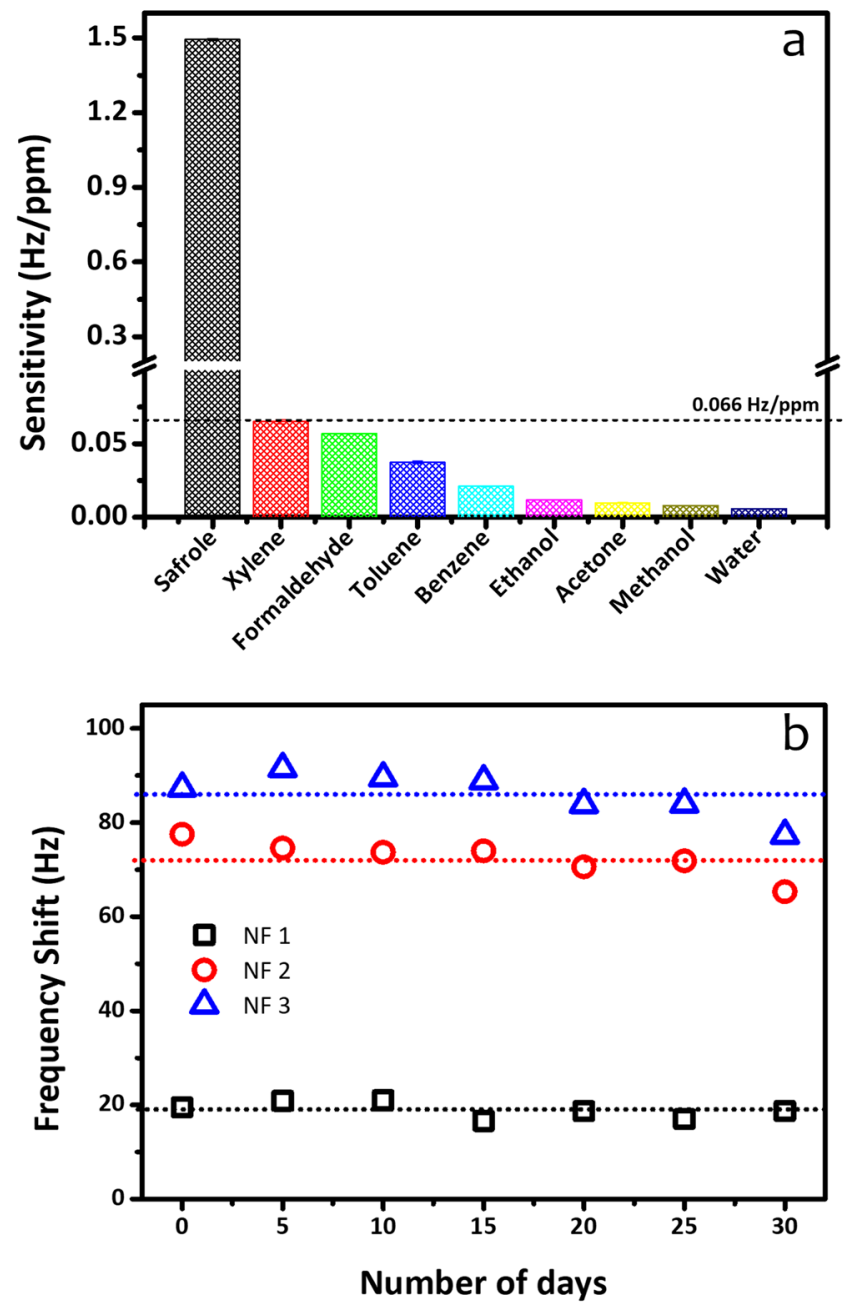

Figure 10. (a) Sensitivity comparison (NF 2 at $50 \mathrm{ppm}$ safrole), and (b) long-term stability measurement of QCM PVAc nanofiber safrole sensor.

(FTIR, Thermo Nicolet iS10) was utilized to understand the chemical reactions between safrole gas and PVAc. The amount of mass deposited on the QCM chip can be calculated according to the Sauerbrey equation ${ }^{34}$, as expressed in Eq. (3):

$$
\Delta f=-\frac{2 f_{0}^{2}}{A \sqrt{\rho_{q} \mu_{q}}} \Delta m
$$

where $\Delta f$ is the resonant frequency shift of QCM (Hz), $f_{0}$ is the base resonant frequency $(10 \mathrm{MHz}), \Delta m$ is the mass change $(\mathrm{g}), A$ is the electrode surface area $\left(0.283 \mathrm{~cm}^{2}\right), \mu_{\mathrm{q}}$ and $\rho_{q}$ are the shear modulus and density of quartz crystal $\left(2.947 \times 10^{11} \mathrm{~g} \cdot \mathrm{cm}^{-1} \cdot \mathrm{s}^{-2}\right.$ and $\left.2.648 \mathrm{~g} \cdot \mathrm{cm}^{-3}\right)$, respectively. The developed PVAc membranes (i.e., NF 0, NF $1, \mathrm{NF} 2$, and NF 3) with different fabrication parameters and masses on the surface of the QCM substrates are listed in Table 1. For cases of created nanofibers, regardless of their similar diameters, it is obvious that the NF 1 and NF 3 samples have the smallest and largest deposited masses, respectively, which differ by one order of magnitude, affecting the performance of the QCM sensors.

Received: 2 May 2019; Accepted: 3 October 2019;

Published online: 28 October 2019

\section{References}

1. Moon, S., Gil, M. \& Lee, K. J. Syringeless Electrospinning toward Versatile Fabrication of Nanofiber Web. Sci. Rep. 7, 41424 (2017).

2. Gnanasekar, S., Kollu, P., Jeong, S. K. \& Grace, A. N. Pt-free, low-cost and efficient counter electrode with carbon wrapped VO2(M) nanofiber for dye-sensitized solar cells. Sci. Rep. 9, 5177 (2019).

3. Miguel, S. P. et al. Electrospun polymeric nanofibres as wound dressings: A review. Colloids Surfaces B Biointerfaces 169, 60-71 (2018).

4. Li, F. et al. Synthesis and characterization of Cr-doped WO3nanofibers for conductometric sensors with high xylene sensitivity. Sensors Actuators, B Chem. 265, 355-364 (2018). 
5. Chotimah et al. Electrical Conductivity Improvement of Polyvinyl Alcohol Nanofiber by Solvent Vapour Treatment. Int. J. Adv. Sci. Eng. Inf. Technol. 6, 675 (2016).

6. Rianjanu, A., Kusumaatmaja, A., Suyono, E. A. \& Triyana, K. Solvent vapor treatment improves mechanical strength of electrospun polyvinyl alcohol nanofibers. Heliyon 4, e00592 (2018).

7. Ding, B., Wang, M., Wang, X., Yu, J. \& Sun, G. Electrospun nanomaterials for ultrasensitive sensors. Mater. Today 13, 16-27 (2010).

8. Ding, B., Wang, M., Yu, J. \& Sun, G. Gas sensors based on electrospun nanofibers. Sensors 9, 1609-1624 (2009).

9. Nugroho, D. B., Rianjanu, A., Triyana, K., Kusumaatmaja, A. \& Roto, R. Quartz crystal microbalance-coated cellulose acetate nanofibers overlaid with chitosan for detection of acetic anhydride vapor. Results Phys. 15, 102680 (2019).

10. Rianjanu, A., Nugroho, D. B., Kusumaatmaja, A., Roto, R. \& Triyana, K. A study of quartz crystal microbalance modified with polyvinyl acetate nanofiber to differentiate short-chain alcohol isomers. Sens. Bio-Sensing Res. 25, 100294 (2019).

11. Wang, Y. et al. A novel ethanol gas sensor based on TiO2/Ag0.35V2O5 branched nanoheterostructures. Sci. Rep. 6, 33092 (2016).

12. Wu, H. et al. One-step Synthesis of Ordered $\mathrm{Pd}_{\mathrm{T}} \mathrm{TiO}_{2}$ Nanofibers Array Film as Outstanding $\mathrm{NH}_{3}$ Gas Sensor at Room Temperature. Sci. Rep. 7, 14688 (2017).

13. Wang, J. et al. High performance hydrazine vapor sensor based on redox mechanism of twisted perylene diimide derivative with lower reduction potential. Sensors Actuators B Chem. 239, 898-905 (2017).

14. Aba, L. et al. Sensitivity Improvement of Ammonia Gas Sensor Based on Poly(3,4-ethylenedioxythiophene):Poly(styrenesulfonate) by Employing Doping of Bromocresol Green. J. Nanotechnol. 2014, 1-5 (2014).

15. He, K., Wang, X., Meng, X., Zheng, H. \& Suye, S. I. Amperometric determination of hydroquinone and catechol on gold electrode modified by direct electrodeposition of poly(3,4-ethylenedioxythiophene). Sensors Actuators, B Chem. 193, 212-219 (2014).

16. Evyapan, M., Kadem, B., Basova, T. V., Yushina, I. V. \& Hassan, A. K. Study of the sensor response of spun metal phthalocyanine films to volatile organic vapors using surface plasmon resonance. Sensors Actuators B Chem. 236, 605-613 (2016).

17. Wang, S.-Y. et al. Surface acoustic wave ammonia sensor based on $\mathrm{ZnO} / \mathrm{SiO} 2$ composite film. J. Hazard. Mater. 285, 368-374 (2015).

18. Rianjanu, A. et al. Polyacrylonitrile nanofiber as polar solvent N,N-dimethyl formamide sensor based on quartz crystal microbalance technique. J. Phys. Conf. Ser. 1011, 012067 (2018).

19. Sabri, Y. M. et al. Gold nanospikes based microsensor as a highly accurate mercury emission monitoring system. Sci. Rep. 4, 6741 (2014).

20. Fulgione, A. et al. QCM-based immunosensor for rapid detection of Salmonella Typhimurium in food. Sci. Rep. 8, 16137 (2018).

21. Su, J., Charmchi, M. \& Sun, H. A Study of Drop-Microstructured Surface Interactions during Dropwise Condensation with Quartz Crystal Microbalance. Sci. Rep. 6, 35132 (2016).

22. Li, J. et al. Adsorption-Desorption Control of Fibronectin in Real Time at the Liquid/Polymer Interface on a Quartz Crystal Microbalance by Thermoresponsivity. Biomacromolecules 20, 1748-1755 (2019).

23. Tokura, Y. et al. Ultrasensitive Detection of Methylmercaptan Gas Using Layered Manganese Oxide Nanosheets with a Quartz Crystal Microbalance Sensor. Anal. Chem. 89, 12123-12130 (2017).

24. Rianjanu, A. et al. Polyvinyl Acetate Film-Based Quartz Crystal Microbalance for the Detection of Benzene, Toluene, and Xylene Vapors in Air. Chemosensors 7, 20 (2019).

25. Rodríguez-Pardo, L., Rodríguez, J. F., Gabrielli, C., Perrot, H. \& Brendel, R. Sensitivity, noise, and Resolution in QCM sensors in liquid media. IEEE Sens. J. 5, 1251-1256 (2005).

26. Julian, T. et al. Quartz crystal microbalance coated with PEDOT-PSS/PVA nanofiber for a high-performance humidity sensor. J. Sensors. Sens. Syst. 8, 243-250 (2019).

27. Rianjanu, A. Quartz Crystal Microbalance Modified with Polymer Nanofiber Layer for the Detection of Organic Compounds. Ph.D. thesis, Universitas Gadjah Mada, Yogyakarta, Indonesia (2019).

28. Triyana, K. et al. Chitosan-Based Quartz Crystal Microbalance for Alcohol Sensing. Electronics 7, 181 (2018).

29. Rianjanu, A. et al. Swelling Behavior in Solvent Vapor Sensing based on Quartz Crystal Microbalance (QCM) Coated Polyacrylonitrile (PAN) Nanofiber. IOP Conf. Ser. Mater. Sci. Eng. 367, 012020 (2018).

30. Zhang, K., Fan, G., Hu, R. \& Li, G. Enhanced Dibutyl Phthalate Sensing Performance of a Quartz Crystal Microbalance Coated with Au-Decorated ZnO Porous Microspheres. Sensors 15, 21153-21168 (2015).

31. Zhang, D. et al. Facile fabrication of high-performance QCM humidity sensor based on layer-by-layer self-assembled polyaniline/ graphene oxide nanocomposite film. Sensors Actuators B Chem. 255, 1869-1877 (2018).

32. Lodge, M. S. et al. Lubricity of gold nanocrystals on graphene measured using quartz crystal microbalance. Sci. Rep. 6, 1-7 (2016).

33. Lu, H. L., Lu, C. J., Tian, W. C. \& Sheen, H. J. A vapor response mechanism study of surface-modified single-walled carbon nanotubes coated chemiresistors and quartz crystal microbalance sensor arrays. Talanta 131, 467-474 (2015).

34. Sauerbrey, G. Verwendung von Schwingquarzen zur Wägung dünner Schichten und zur Mikrowägung. Zeitschrift für Phys. 155, 206-222 (1959).

35. Pinalli, R. et al. Detection of amphetamine precursors with quinoxaline-bridged cavitands. Supramol. Chem. 25, 682-687 (2013).

36. Hackner, A. et al. Surface ionization detection of amine containing drugs. Sensors Actuators, B Chem. 185, 771-776 (2013).

37. Rianjanu, A. et al. Polyacrylonitrile Nanofiber-Based Quartz Crystal Microbalance for Sensitive Detection of Safrole. Sensors 18, 1150 (2018).

38. Rianjanu, A. et al. An enhanced safrole sensing performance of a polyacrylonitrile nanofiber-based-QCM sensor by overlaying with chitosan. Sains Malaysiana 48, (2019).

39. Honeychurch, K. Review: The Application of Liquid Chromatography Electrochemical Detection for the Determination of Drugs of Abuse. Separations 3, 28 (2016).

40. Saito, K. et al. Analysis of drugs of abuse in biological specimens. J. Heal. Sci. 57, 472-487 (2011).

41. Liu, L. L. \& Stephan, D. W. Radicals derived from Lewis acid/base pairs. Chem. Soc. Rev. 48, 3454-3463 (2019).

42. Ding, X., Chen, X., Chen, X., Zhao, X. \& Li, N. A. QCM humidity sensor based on fullerene/graphene oxide nanocomposites with high quality factor. Sensors Actuators B Chem. 266, 534-542 (2018).

43. Wasisto, H. S. et al. Airborne engineered nanoparticle mass sensor based on a silicon resonant cantilever. Sensors Actuators $B$ Chem. 180, 77-89 (2013).

44. Wasisto, H. S., Zhang, Q., Merzsch, S., Waag, A. \& Peiner, E. A phase-locked loop frequency tracking system for portable microelectromechanical piezoresistive cantilever mass sensors. Microsyst. Technol. 20, 559-569 (2014).

45. Wasisto, H. S. et al. Portable cantilever-based airborne nanoparticle detector. Sensors Actuators B Chem. 187, 118-127 (2013).

46. Wasisto, H. S., Merzsch, S., Uhde, E., Waag, A. \& Peiner, E. Handheld personal airborne nanoparticle detector based on microelectromechanical silicon resonant cantilever. Microelectron. Eng. 145, 96-103 (2015).

47. Bertke, M. et al. Analysis of asymmetric resonance response of thermally excited silicon micro-cantilevers for mass-sensitive nanoparticle detection. J. Micromechanics Microengineering 27, 064001 (2017).

48. Xu, J., Bertke, M., Wasisto, H. S. \& Peiner, E. Piezoresistive microcantilevers for humidity sensing. J. Micromechanics Microengineering 29, 053003 (2019).

49. Merzsch, S. et al. Production of vertical nanowire resonators by cryogenic-ICP-DRIE. Microsyst. Technol. 20, 759-767 (2014).

50. Wasisto, H. S. et al. Femtogram aerosol nanoparticle mass sensing utilising vertical silicon nanowire resonators. Micro Nano Lett. 8 , 554-558 (2013).

51. Wasisto, H. S. et al. Silicon resonant nanopillar sensors for airborne titanium dioxide engineered nanoparticle mass detection. Sensors Actuators, B Chem. 189, 146-156 (2013). 
52. Wasisto, H. S. et al. Evaluation of photoresist-based nanoparticle removal method for recycling silicon cantilever mass sensors. Sensors Actuators, A Phys. 202, 90-99 (2013).

53. Huang, W. et al. Highly sensitive formaldehyde sensors based on polyvinylamine modified polyacrylonitrile nanofibers. RSC Adv. 3 , 22994 (2013)

54. D’Amelia, R. P., Gentile, S., Nirode, W. F. \& Huang, L. Quantitative Analysis of Copolymers and Blends of Polyvinyl Acetate (PVAc) Using Fourier Transform Infrared Spectroscopy (FTIR) and Elemental Analysis (EA). World J. Chem. Educ. 4, 25-31 (2016).

55. Li, Y. \& Ren, S. Adhesives. In Building Decorative Materials 325-341, https://doi.org/10.1533/9780857092588.325 (Elsevier, 2011).

56. Long, G. L. \& Winefordner, J. D. Limit of detection. A closer look at the IUPAC definition. Anal. Chem. 55, 712A-724A (1983).

57. Markiewicz, N. et al. Micro light plates for low-power photoactivated (gas) sensors. Appl. Phys. Lett. 114, 053508 (2019).

58. Casals, O. et al. A Parts Per Billion (ppb) Sensor for $\mathrm{NO}_{2}$ with Microwatt $(\mu \mathrm{W})$ Power Requirements Based on Micro Light Plates. ACS Sensors 4, 822-826 (2019).

59. Wang, $\mathrm{X}$. et al. Functionalized nanoporous $\mathrm{TiO}_{2}$ fibers on quartz crystal microbalance platform for formaldehyde sensor. Sensors Actuators, B Chem. 171-172, 658-665 (2012).

\section{Acknowledgements}

We acknowledge the financial support provided by the Ministry of Research, Technology and Higher Education of the Republic of Indonesia (RISTEKDIKTI) under "Penelitian Terapan" (PT) schemes (Contract No. 2833/ UN1. DITLIT/DIT-LIT/LT/2019). We also thank Mr. Budiarto (Indonesian National Police, Headquarters, Jakarta) for supplying the safrole samples. A. Rianjanu acknowledges a Ph.D. scholarship issued by the Ministry of Research, Technology and Higher Education of the Republic of Indonesia trough PMDSU program. We thank Dr. Setyawan P. Sakti for characterizing the conductance and susceptance of the QCM using a vector network analyzer (Omicron-Lab Bode 100). H.S. Wasisto acknowledges the financial support from Lower Saxony Ministry for Science and Culture (N-MWK) for LENA-OptoSense group and RISTEKDIKTI for Indonesian-German Center for Nano and Quantum Technologies (IG-Nano). H.S. Wasisto and K. Triyana thank the Directorate General of Higher Education, Science, and Technology Resources (Ditjen SDID), RISTEKDIKTI for providing them an opportunity to be involved in an excellent Indonesian diaspora platform of World-Class Scholar Symposium (Simposium Cendekia Kelas Dunia (SCKD)), which has led to establishment of continuous collaboration between domestic and diaspora scientists for accelerating transfer of science and technology and advancing research and development in Indonesia, especially in the fields of nanotechnology and sensors.

\section{Author contributions}

K.T. conceived and designed the experiments, revised the paper, and led the project. A.R. performed experiments, analyzed the data, and wrote the initial paper. D.B.N. and A.H.A. performed the experiments, analyzed the data. A.K. and R.R. designed the experiments, contributed reagents and materials, analyzed the data, and revised the paper. R.S. performed AFM measurement and analyzed the data. H.S.W. analyzed the data and revised the paper. All authors confirmed the final manuscript

\section{Competing interests}

The authors declare no competing interests.

\section{Additional information}

Correspondence and requests for materials should be addressed to K.T.

Reprints and permissions information is available at www.nature.com/reprints.

Publisher's note Springer Nature remains neutral with regard to jurisdictional claims in published maps and institutional affiliations.

(c) (1) Open Access This article is licensed under a Creative Commons Attribution 4.0 International License, which permits use, sharing, adaptation, distribution and reproduction in any medium or format, as long as you give appropriate credit to the original author(s) and the source, provide a link to the Creative Commons license, and indicate if changes were made. The images or other third party material in this article are included in the article's Creative Commons license, unless indicated otherwise in a credit line to the material. If material is not included in the article's Creative Commons license and your intended use is not permitted by statutory regulation or exceeds the permitted use, you will need to obtain permission directly from the copyright holder. To view a copy of this license, visit http://creativecommons.org/licenses/by/4.0/.

(C) The Author(s) 2019 